\title{
Modelo referencial para a avaliação da Acessibilidade Comunicacional em políticas de comunicação interna de hospitais universitários
}

Reference model for evaluation of Communication Accessibility in Internal Communication Policies of University Hospitals

Modelo referencial para evaluación de La Accesibilidad Comunicacional en Políticas de Comunicación Interna de Hospitales Universitarios

DOI: https://doi.org/10.1590/1809-58442021213

\section{Francisco Ricardo Duarte ${ }^{1}$}

https://orcid.org/0000-0002-9102-8273

\section{Allan Richards de Melo Nunes Morais ${ }^{1}$}

https://orcid.org/0000-0002-4828-2583

${ }^{1}$ (Universidade Federal do Vale do São Francisco, Mestrado Profissional em Administração Pública. Juazeiro - BA, Brasil).

\section{Resumo}

Os hospitais públicos necessitam de uma gestão pautada na garantia de acesso equânime aos serviços assistenciais e educacionais. Para tanto, "a comunicação se coloca como uma estratégia importante na construção de um novo paradigma de relacionamento com seus públicos” (NASSAR, 2006a, p. 2). Em Hospitais Universitários, a Política de Comunicação Interna deve assimilar os princípios da Acessibilidade Comunicacional, a fim de subsidiar aspectos assistenciais e acadêmicos. Sendo assim, o presente estudo propõe e aplica o "Modelo referencial para avaliação da Acessibilidade Comunicacional em Políticas de Comunicação Interna de Hospitais Universitários” enquanto instrumento avaliativo para a elaboração e o diagnóstico de políticas endocomunicacionais inclusivas. Demonstrando a validade do instrumento proposto, foi analisado um documento intitulado "Diretrizes de Comunicação Institucional e Normativa Interna da Unidade de Comunicação Social do HU-Univasf”, o qual recebeu parecer negativo. Sendo assim, relata-se a Pesquisa Qualitativa, Descritiva e Documental, baseada nas etapas de Revisão de Literatura, em Pesquisa Documental e Triangulação de Dados.

Palavras-chave: Acessibilidade Comunicacional. Comunicação Interna. Avaliação de políticas de comunicação. Hospitais Universitários. Gestão Pública. 


\begin{abstract}
Public hospitals need management based on an equitable ensuring of access to care and educational services. With this aim, "communication is an important strategy in the construction of a new paradigm of relationship with its publics”(NASSAR, 2006a, p. 2).In University Hospitals, the Internal Communication Policy must assimilate the principles of Communicational Accessibility in order to subsidize care and academic aspects. Therefore, the present study proposes and applies the "Reference model for evaluation of Communication Accessibility in Internal Communication Policies of University Hospitals". This tool assists in the elaboration and diagnosis of inclusive internal communication policies. The document entitled "Guidelines for Institutional Communication and Internal Regulations of the Social Communication Unit of HU-Univasf” was analyzed in order to demonstrate the validity of the proposed instrument.This document received a negative evaluation. Thus, we report the Qualitative, Descriptive and Documentary Research, based on the stages of Literature Review, Documentary Research and Data Triangulation.
\end{abstract}

Keywords: Communicational Accessibility. Internal communication. Evaluation of communication policies. University Hospitals. Public administration.

\title{
Resumen
}

Los hospitales públicos necesitan una gestión pautada en la garantía de acceso equitativo a los servicios asistenciales y educativos. Para ello, "la comunicación se plantea como una estrategia importante en la construcción de un nuevo paradigma de relación con sus públicos” (NASSAR, 2006a, p. 2). En Hospitales Universitarios, la Política de Comunicación Interna debe asimilar los principios de la Accesibilidad Comunicacional a fin de subsidiar aspectos asistenciales y académicos. Por lo tanto, el presente estudio propone y aplica el "Modelo referencial para evaluación de la Accesibilidad Comunicacional en Políticas de Comunicación Interna de Hospitales Universitarios” como instrumento de evaluación para la elaboración y diagnóstico de políticas endocomunicacionales inclusivas. Demostrando la validez del instrumento propuesto, se analizó un documento titulado "Directrices de Comunicación Institucional y Normativa Interna de la Unidad de Comunicación Social del HU-Univasf”, el cual recibió un parecer negativo. Siendo así, se relata la Investigación Cualitativa, Descriptiva y Documental, basada en las etapas de Revisión de Literatura, Investigación Documental y Triangulación de Datos.

Palabras clave: Accesibilidad Comunicacional. Comunicación interna. Evaluación de las políticas de comunicación. Hospitales Universitarios. Gestión pública.

\section{Introdução}

Os processos de gestão e operacionalização das funções públicas se configuram como uma demanda desafiadora (WRIGHT; KROLL; PARNELL, 2000, SILVA; ASSIS, 2016, NOGUEIRA; REINALDO; MAYER, 2013). Na busca pela garantia da prestação 
de serviços de forma eficiente e equânime, a Comunicação Interna, ou Endocomunicação, torna-se importante recurso, sobretudo em instituições públicas polivalentes, como é o caso dos Hospitais Universitários (HUs), que atuam simultaneamente no cenário educacional e de promoção de saúde (NASSAR, 2008).

Visando subsidiar as atividades organizacionais em HUs, sob a égide da igualdade no acesso aos serviços assistenciais e educacionais, independentemente das especificidades motoras ou cognitivas dos indivíduos assistidos, a Comunicação Interna (CI) requer planejamento e respaldo institucionais contemplados em uma Política de Comunicação bem delineada (VIGNERON, 2000, ABRACOM, 2008, BUENO, 2014, 2014b, 2014c).

Para tanto, a arquitetura dessas Políticas deve ser pautada nos preceitos normativos e científicos que tratam sobre o desenvolvimento endocomunicacional no âmbito público hospitalar. Conforme abordado no presente artigo, essa articulação legal (jurídica) e acadêmica fornece o referencial de boas práticas para a elaboração e a avaliação de políticas comunicacionais internas dotadas do atributo da Acessibilidade Comunicacional (SASSAKI, 2006, 2009, BORGES, 2014, SARRAF, 2016, SARDAGNA; OLIVEIRA, 2017, PIMENTEL; PIMENTEL, 2017, ALVES, 2019, FIGUEIRA, 2019).

Diante disso, inserindo-se no campo da Comunicação Organizacional (TORQUATO, 2002), o presente estudo propõe e aplica um instrumento de avaliação baseado em parâmetros da literatura científica e normativas legais para verificar a inserção do predicativo da Acessibilidade Comunicacional na configuração das Políticas Endocomunicacionais dos HUs. Os critérios que compõem o instrumento intitulado de "Modelo referencial para a avaliação da Acessibilidade Comunicacional em Políticas de Comunicação Interna de Hospitais Universitários” estão descritos em seção subsequente.

Nesse sentido, buscando demonstrar a pertinência do referencial avaliativo ora proposto, este artigo relata a análise do documento nominado "Diretrizes de Comunicação Institucional e Normativa Interna da Unidade de Comunicação Social do Hospital Universitário da Univasf", com o intuito de averiguar se este cumpre requisitos de Acessibilidade Comunicacional. Essas Diretrizes congregam a Política de Comunicação Interna e Externa do HU-Univasf, estabelecendo, assim, os princípios, instruções e padronizações de procedimentos comunicacionais a serem adotados no âmbito hospitalar (HU-UNIVASF, 2017).

O hospital federal em questão encontra-se localizado no município de Petrolina-PE, sendo, pois, a única referência pública da região para atendimento das demandas de urgência e emergência, em média e alta complexidade, provenientes da rede interestadual de saúde formada por 54 municípios da Bahia e Pernambuco. O HU-Univasf é campo de estágio para os cursos de graduação oriundos de nove instituições de ensino superior e sete escolas técnicas localizadas nas regiões Norte, Nordeste e Sudeste. A unidade conta, ainda, com 13 programas de residência em diversas áreas da saúde. 


\section{Estado da arte da pesquisa}

\section{A acessibilidade comunicacional}

As iniciativas que almejam a inteligibilidade dos conteúdos informacionais dizem respeito a um atributo de maior envergadura, o qual se torna imprescindível no contexto da democratização dos serviços públicos; trata-se, nesse contexto de discussão, da Acessibilidade Comunicacional (SASSAKI, 2006, 2009, BORGES, 2014, SARRAF, 2016, SARDAGNA; OLIVEIRA, 2017, PIMENTEL; PIMENTEL, 2017, ALVES, 2019, FIGUEIRA 2019).

Sassaki $(2006,2009)$ aborda a Acessibilidade Comunicacional sob o prisma do processo de troca de informações. Segundo o autor, para ser considerado acessível, esse processo deve ocorrer destituído de quaisquer barreiras, ruídos, ou limitações comunicacionais existentes entre pessoas com ou sem deficiência.

Corroborando a premissa de Sassaki (2006, 2009), Borges (2014) evidencia ainda que a incorporação do atributo de acessibilidade nas mais diversas áreas de atuação humana, sobretudo na comunicação, torna-se basilar para a garantia de direitos e emancipação do indivíduo. Principalmente quando levado em consideração o contexto da era informacional e da mediação/virtualização das experienciais sociais vivenciado atualmente.

Nesse contexto, vários aspectos da vida cotidiana, desde a obtenção de serviços governamentais (certidões, benefícios, seguridade social, atendimento institucional etc.), assim como diversas formas de lazer/entretenimento (mídias sociais, streaming, sistemas de chat etc.) são acessados e experimentados através dos meios de comunicação. Nessa perspectiva, explicam Sardagna e Oliveira (2017), os atributos de acessibilidade e inclusão tornam-se interdependentes; pois, dispor de serviços (estatais ou privados) e participar ativamente da tessitura social através de ferramentas de comunicação acessíveis são condições fundamentais para que o indivíduo se compreenda efetivamente integrado (PIMENTEL; PIMENTEL, 2017).

No entanto, o processo de desenvolvimento de espaços e rotinas dotados de Acessibilidade Comunicacional é complexo e abarca variáveis estruturais (físicas) e atitudinais (comportamentais), entre outras. Investir em tecnologia e pesquisa, promover políticas públicas voltadas ao fomento da comunicação acessível e propiciar a participação ativa das pessoas com deficiência na construção de soluções em comunicação e informação é um caminho promissor para a efetividade dos recursos de adaptações ou inovações comunicacionais voltadas à inclusão (FIGUEIRA, 2019).

Além disso, é necessário desenvolver estratégias comunicativas diferenciadas capazes de estabelecer novos fluxos informacionais entre pessoas com ou sem limitações motoras e/ou cognitivas. Sarraf (2016) recomenda a adoção de uma comunicação sensorial capaz de explorar concomitantemente as diversas possibilidades de interação dos indivíduos com o meio (olfato, paladar, tato, audição, visão etc.) como estratégia para dirimir possíveis barreiras comunicacionais causadas pela deficiência. 
Não obstante, a Acessibilidade Comunicacional somente será viabilizada quando alicerçada em uma sociedade que apresente comportamentos e relações verdadeiramente inclusivas, capaz de mitigar, portanto, as barreiras atitudinais que impedem a real integração das pessoas com deficiência. Esse cenário, por sua vez, é reflexo de um processo de educação inclusiva, o qual requer a participação das mais diversas instâncias sociais, desde a família até as organizações civis, meios de comunicação e entes governamentais (FIGUEIRA, 2019).

Portanto, a Acessibilidade Comunicacional pode ser compreendida como o atributo da comunicação desenvolvida a partir do emprego de recursos tecnológicos, comportamentais, ambientais, relacionais e estratégias informacionais, objetivando um processo comunicacional verdadeiramente equânime entre pessoas, independentemente das suas especificidades motoras e/ou cognitivas (SASSAKI, 2006, 2009, BORGES, 2014, SARRAF, 2016, SARDAGNA; OLIVEIRA, 2017, PIMENTEL; PIMENTEL, 2017, ALVES, 2019, FIGUEIRA 2019). Esse tema foi abordado na presente pesquisa sob o enfoque das ações que visam promover a superação de barreiras comunicacionais na prestação de serviços em HUs.

\section{Diretrizes legais sobre acessibilidade em saúde}

Para fins de implementação de serviços públicos, a Lei $n^{0}$ 13.146, de 6 de julho de 2015, determina o cumprimento e a efetivação do atributo da Acessibilidade, sendo, dessa forma, definida como: possibilidade e condição de alcance para utilização, com segurança e autonomia, de espaços, mobiliários, equipamentos urbanos, edificações, transportes, informação e comunicação, inclusive seus sistemas e tecnologias, bem como de outros serviços e instalações abertos ao público, de uso público ou privados de uso coletivo, tanto na zona urbana como na rural, por pessoa com deficiência ou com mobilidade reduzida (BRASIL, 2015).

No escopo das garantias de acesso das pessoas com deficiência aos serviços de saúde, a referida lei assegura, entre outras direitos, atenção integral à saúde em todos os níveis de complexidade, com acesso universal e igualitário, seguindo normas éticas e técnicas e considerando aspectos relacionados aos direitos e às especificidades da pessoa com deficiência, incluindo temas como sua dignidade e autonomia (BRASIL, 2015).

Ademais, o imperativo da acessibilidade no escopo da saúde é versado com maior detalhamento pela Portaria n ${ }^{\circ}$ 793, de 24 de abril de 2012 do Ministério da Saúde, que institui a Rede de Cuidados à Pessoa com Deficiência. Dentre as principais normativas de operacionalização da Rede, estão o

respeito aos direitos humanos, com garantia de autonomia, independência e de liberdade às pessoas com deficiência para fazerem as próprias escolhas; a promoção da equidade; promoção do respeito às diferenças e aceitação de 
pessoas com deficiência, com enfrentamento de estigmas e preconceitos; garantia de acesso e de qualidade dos serviços, ofertando cuidado integral e assistência multiprofissional, sob a lógica interdisciplinar; atenção humanizada e centrada nas necessidades das pessoas e diversificação das estratégias de cuidado (BRASIL, 2012, p. 2).

Depreende-se que, para serem acessíveis, os serviços e os ambientes de serviço devem possuir características assimiláveis à maior gama possível de indivíduos, apresentando, para tanto, as adaptações e recursos necessários para o acolhimento adequado das pessoas com deficiência (PIMENTEL; PIMENTEL, 2017, ALVES, 2019, FIGUEIRA 2019).

\section{Iniciativas em acessibilidade e tecnologias assistivas no âmbito do SUS}

Diante das demandas sociais, repercutindo nos marcos legislativos supracitados, algumas iniciativas de pesquisa e adoção de tecnologias assistivas têm contribuído para a incorporação do atributo da acessibilidade em hospitais e demais unidades da rede pública. Nesse sentido, instituições de saúde têm desenvolvido estratégias de capacitação para que os profissionais da área estejam aptos a adotar instrumentos e comportamentos acessíveis no processo de acolhimento, diagnóstico e tratamento de pacientes com limitações motoras e/ ou cognitivas.

Os cursos “Acessibilidade e os Princípios do SUS-FIOCRUZ” e "Uso Terapêutico de Tecnologias Assistivas-UFMG”, voltados para profissionais de saúde, são exemplos de iniciativas que visam a formação interdisciplinar e adoção de recursos de acessibilidade na saúde pública. Empregando multimeios (escrita, vídeos, aulas virtuais, entre outros), as formações oferecidas pelo SUS abordam aspectos técnicos e comportamentais, visando a promoção do cuidado inclusivo e acessível (FIGUEIREDO et al., 2015, RESENDE et al., 2015, ALVES, 2019).

Adoção de piso podotátil, macas e mesas com regulagem de altura, espaços com manobrabilidade para cadeira de rodas, cores de ambientação com alto contraste e emprego de órteses e próteses eletrônicas ou analógicas são alguns dos recursos assistivos de ordem técnica apresentados durantes as capacitações. Além disso, os profissionais são instruídos quanto aos comportamentos inclusivos no processo de atendimento, tais como narrar toda a movimentação e aproximação quando diante de pessoas cegas, utilizar a língua brasileira de sinais, articular bem as palavras para facilitar a leitura labial, entre outros (ALVES, 2019).

Apesar dessas iniciativas positivas, pesquisas que visam avaliar o nível de assimilação do atributo de acessibilidade nas unidades de saúde, sobretudo quanto a aspectos arquitetônicos, urbanísticos e de disponibilidade de recursos assistivos, revelam que ainda há um longo caminho a ser percorrido até que a rede assistencial brasileira seja considerada efetivamente acessível (GALVAN et al., 2019, FALCÃO, 2016, FIGUEIRA, 2019, PIMENTEL; PIMENTEL, 2017, SCHMENGLER; FREITAS; PAVÃO, 2018). 
Diante disso, os pesquisadores têm proposto uma série de soluções em inovação e adaptação visando dirimir as barreiras comunicacionais e ambientais enfrentadas pelas pessoas com deficiência. Bandejas ergonômicas e compartimentalizadas para a dispensação de medicamentos; muletas adaptadas às especificidades motoras do paciente; instrumentos de alimentação adaptados; tecnologia de vapor aquecido para banho e sistema de higiene oral para pacientes acamados; cadeiras ergonômicas adaptadas para conversão em macas e aplicativos para celular voltados à maximização dos recursos comunicacionais das pessoas com deficiência são alguns exemplos de tecnologias assistivas propostas visando a maior autonomia e inclusão dos pacientes com limitações motoras e/ou cognitivas (MORO et al., 2008, MIRENO et al., 2018, DESIMON; BATIZ, 2012, RAMÃO, 2017, ANJOS, 2018, FALCÃO, 2016).

\section{Acessibilidade Comunicacional na endocomunicação em Hospitais Universitários}

Com foco no papel ambivalente (emissor e receptor) das pessoas com deficiência no fluxo informacional, oferecendo subsídios para a construção de um ambiente inclusivo, a Acessibilidade Comunicacional é a que prevê a "ausência de barreiras na comunicação interpessoal envolvendo língua de sinais, escrita de jornal, revista, livro, carta, apostila, etc., incluindo textos em Braille, uso do computador portátil e acessibilidade digital” (SARDAGNA; OLIVEIRA, 2017, p. 7).

A promoção de um cenário comunicacional acessível requer esforços técnicos e culturais. No contexto acadêmico, Castro e Almeida (2014, p. 79) destacam “os grandes desafios para as universidades diante do acesso dos alunos com deficiência: romper as barreiras ainda existentes (principalmente, as atitudinais); prever e prover condições de acessibilidade (física, comunicacional e pedagógica)”. Essas barreiras comunicacionais podem se manifestar na forma de qualquer entrave que dificulte ou impossibilite a expressão ou o recebimento de mensagens por intermédio dos meios ou sistemas de comunicação, sejam ou não de massa (BRASIL, 2000).

Em HUs, a Comunicação Interna, quando desenvolvida sob a perspectiva da acessibilidade, pode contribuir para a democratização do acesso aos serviços de saúde. Conforme explana Silva (2014), em seu estudo sobre a análise ambiental desses espaços, a fim de dirimir tais barreiras, o uso de recursos de comunicação e de tecnologia assistiva “poderá contribuir para um espaço acessível, pois, quando o usuário compreende e utiliza o espaço sem dificuldade, ele se sente mais seguro, autônomo e independente” (SILVA, 2014, p. 92).

Como é possível observar, “incluir comunicacionalmente” demanda prezar pela inexistência de barreiras (ruídos de mensagens ou inoperância de canais) e, simultaneamente, depreender esforços para prover multimeios de acesso equânime à informação. Sendo assim, no contexto dos Hospitais Universitários, que atendem uma heterogênea gama populacional, 
torna-se indispensável primar pela inclusão em comunicação, a qual deve ser dirigida não somente aos pacientes, como também a todos os profissionais e estudantes que atuam nessas unidades de saúde.

Destarte, a Acessibilidade Comunicacional em saúde deve contribuir para a emancipação dos indivíduos, considerando que a progressão da "autonomia das pessoas com deficiência não depende apenas do acesso ao diagnóstico, à reabilitação e à concessão de órteses, próteses e outras tecnologias assistivas. Depende de ambiências sem barreiras arquitetônicas, comunicacionais e atitudinais” [...] (MENDES, 2014, p. 37).

Diante da necessidade de promoção de um cenário comunicacional efetivamente democrático, capaz de estabelecer relações e permitir uma participação social mais abrangente, a Acessibilidade Comunicacional é imprescindível na configuração dos processos informacionais públicos. Dessa forma, é esperado que as políticas endocomunicacionais contemplem recursos inclusivos objetivando assegurar o acesso às fontes de informação e canais de interação por todos os indivíduos que compõem o público institucional interno.

Sobre esse imperativo, Oliveira (2012, p. 49) explica que as “políticas de comunicação devem levar em consideração as questões fundamentais, como a garantia de participação de todos no âmbito organizacional, já que a democracia deve ir além da esfera estatal”. No contexto universitário e hospitalar público, as especificidades cognitivas, características sociais e demais particularidades dos públicos interno e externo devem ser contempladas no planejamento e execução das atividades de comunicação, promovendo, pois, um ambiente inclusivo e acolhedor (CASTRO; ALMEIDA, 2014, SILVA, 2014, PIMENTEL; PIMENTEL, 2017, ALVES, 2019, FIGUEIRA, 2019).

\section{A importância da avaliação das políticas comunicacionais}

Para a garantia da Acessibilidade Comunicacional em Hospitais Universitários, assim como nas demais instituições, é imperioso um planejamento adequado que contemple, em seu arcabouço, os aspectos técnicos, estruturais, legais e culturais alinhados ao desenvolvimento da missão hospitalar, bem como às especificidades comunicacionais dos públicos (PINHO, 1991, DUARTE, 2007a, 2007b, ARMANI, 2008, KUNSCH, 2012, BELTRAME; ALPERSTEDT, 2014, BUENO, 2014, 2014b, 2014c).

Sendo assim, objetivando verificar a conformidade das políticas endocomunicacionais em hospitais de ensino, é preciso que haja um referencial para que tais documentos sejam elaborados ou avaliados, a fim de serem corrigidas as possíveis distorções quanto à finalidade e abrangência das políticas. A imprescindibilidade de avaliação de Políticas de Comunicação é corroborada por Bueno (2015a, 2015b). Para o autor, é necessário aferir periodicamente a eficiência e relevância da Política de Comunicação; sempre buscando aperfeiçoá-la e reintegrá-la à realidade institucional e social. Caso contrário, ela será “atropelada” pela mudança das condições, dos contextos em que ela originalmente foi gerada (BUENO, 2015a). 
Ratificando esse raciocínio, Nunes (2014) explica que as instituições públicas de ensino superior precisam estar atentas para a necessidade de uma elaboração adequada e avaliação das políticas comunicacionais. Ainda segunda a autora,

a definição de Políticas é fundamental para o direcionamento de estratégias que visem o relacionamento positivo com todos os agentes com influência. Portanto, ao elaborar as suas políticas de comunicação, a universidade deve observar qual é a missão e os objetivos assumidos perante sua comunidade (NUNES, 2014, p. 8).

Em um hospital universitário, os principais resultados institucionais esperados se relacionam à prestação de serviço em educação e saúde de maneira equânime. Nesse sentido, a Política de Comunicação Interna deve contemplar a provisão de recursos comunicacionais capazes de influenciar positivamente o caráter democrático e igualitário das atividades educacionais e assistenciais baseados em uma comunicação acessível.

No entanto, uma vez que tais requisitos não tenham sido observados desde a fase de elaboração da Política, torna-se necessária a avaliação desses documentos. Segundo Armani (2008), Nunes (2014) e Bueno (2015a, 2015b), o diagnóstico de uma Política Comunicacional deve ser feito de maneira sistemática, o que implica em estabelecimento de critérios claros e bem fundamentados. Diante desse imperativo, apresenta-se a seguir o percurso metodológico utilizada na concepção do "Modelo referencial para avaliação das boas práticas em Acessibilidade Comunicacional nas Políticas de Comunicação Interna de Hospitais Universitários”.

\section{Percurso metodológico}

\section{Classificação da pesquisa e coleta de dados}

O trabalho ora delineado enquadra-se como pesquisa qualitativa. Segundo Creswell (2007, p. 187), “a pesquisa qualitativa é fundamentalmente interpretativa. Isso significa que o pesquisador faz uma interpretação dos dados, o que inclui o desenvolvimento da descrição de uma pessoa ou de um cenário, análise de dados para identificar temas ou categorias”. Portanto, destaca-se o viés qualitativo desta pesquisa, a qual se apoiou em métodos não quantificáveis, com enfoque no caráter interpretativo alicerçado no respaldo teórico, para a coleta e análise dos dados.

Ademais, o trabalho ora exposto caracteriza-se também enquanto pesquisa descritiva, tendo, portanto, o objetivo de expor as características do objeto de estudo (VERGARA, 2013, p. 42). Esse tipo de pesquisa viabiliza investigar os atributos das atividades de instituições públicas, como é o caso do HU-Univasf, sendo "habitualmente realizada por pesquisadores 
sociais preocupados com a atuação prática. São as mais solicitadas por organizações como instituições educacionais” (GIL, 2008, p. 28).

O estudo em questão recorreu à pesquisa bibliográfica (VERGARA, 2013). Segundo entendimento de Vergara (2013, p. 43), esse tipo de pesquisa consiste "no estudo sistematizado desenvolvido com base em material publicado em livros, revistas, jornais, redes eletrônicas, isto é, material acessível ao público em geral”, possibilitando ao pesquisador “compreender em que estado exploratório se encontra, atualmente, o problema estudado, quais trabalhos já foram realizados a respeito e, por sua vez, quais as opiniões reinantes sobre o assunto” (MARCONI; LAKATOS, 2003, p. 186). Por conseguinte, o cumprimento dessa etapa subsidiou a compreensão do referencial teórico avaliativo a ser utilizado na análise da política comunicacional do HU-Univasf.

A pesquisa documental, por meio da apreciação de escritos documentais, a exemplo dos memorandos, ofícios, da legislação aplicada à instituição, regimentos e manuais, entre outros (MARCONI; LAKATOS, 2002, GIL, 2008), também foi empregada no presente trabalho. Assim, pôde o pesquisador inteirar-se das diretrizes legais, normativas institucionais, além de outros documentos que norteiam as boas práticas em Políticas Endocomunicacionais no âmbito dos hospitais universitários.

\section{Procedimentos de análise de dados}

Prodanov e Freitas (2013, p. 129) conceituam a técnica da Triangulação enquanto "processo de comparação entre dados oriundos de diferentes fontes no intuito de tornar mais convincentes e precisas as informações obtidas”. Dessa forma, o trabalho aqui proposto submeteu os dados obtidos de diferentes fontes e métodos de coleta à contrastação mútua a fim de observar a existência de validação das informações de pesquisa. Essa atividade configura a “Triangulação de Dados” (SAMPIERI; COLLADO; LUCIO, 2013).

Os achados provenientes das etapas de coleta e análise de dados encontram-se no tópico subsequente deste artigo. A apresentação de resultados é feita através de uma articulação multifatorial de aspectos legais/acadêmicos, objetivos/subjetivos, provenientes da Revisão de Literatura e da Pesquisa Documental, de natureza conceitual e prática.

Portanto, a Triangulação de Dados permitiu convergir essas variáveis de maneira criteriosa, a fim de se obter a fundamentação científica necessária para embasar as considerações feitas pelo autor sobre a proposição e aplicação do "Modelo referencial para avaliação da Acessibilidade Comunicacional em Políticas de Comunicação Interna de Hospitais Universitários”. 


\section{Resultados}

\section{Conhecendo o objeto de análise: Diretrizes de Comunicação Institucional e Normativa Interna da Unidade de Comunicação Social do Hospital Universitário da Univasf}

A seguir, apresenta-se brevemente a estrutura e conteúdo das "Diretrizes de Comunicação Institucional e Normativa Interna da Unidade de Comunicação Social do Hospital Universitário da Univasf”; documento responsável pelo delineamento da Política Endocomunicacional hospitalar. A abertura das Diretrizes é feita através dos tópicos denominados “Apresentação” e Introdução”. Já no “Pressupostos Básicos”, as referidas Diretrizes estabelecem os princípios norteadores das atividades comunicacionais, quais sejam: transparência, ética, credibilidade, excelência, responsabilidade social, sustentabilidade, inovação e igualdade.

Sequencialmente, observa-se o tópico “Objetivos da comunicação social do HUUnivasf”, que insere os eixos motivadores das ações e projetos comunicacionais no Hospital Universitário. Já o item "Linhas de trabalho" se destina a demarcar as áreas de atuação das atividades comunicacionais a serem desenvolvidas (HU-UNIVASF, 2017); são essas: “Desenvolvimento de rotinas comunicacionais"; "Diagnóstico comunicacional”; "Criação e manutenção de canais e produtos”; "Estruturação/ documentação” e "Capacitação e qualificação em comunicação”.

Adiante, no tópico "Públicos de Interesse", as Diretrizes identificam as categorias de indivíduos que compõem a comunidade hospitalar. Esses grupos estão alocados em duas categorias denominadas “Público Interno” e "Público Externo”. No escopo do Público Interno, encontram-se os grupos de usuários; colaboradores; alunos; familiares e colaboradores de instituições parceiras. Após a especificação dos públicos institucionais, são demarcadas as normativas que norteiam variáveis a serem consideradas no processo de interação com esses grupos, o que está registrado na subdivisão “Relação com os públicos de interesse”.

O item subsequente é intitulado "Da hierarquização, canais e fluxos internos e externos de comunicação”. Entre outros temas, esse tópico define a escala de priorização a ser aplicada no desenvolvimento das atividades comunicacionais do HU. Mais à frente, a subdivisão “Dos canais de comunicação interna e externa do HU-Univasf” é responsável por enumerar os meios comunicacionais e suas aplicabilidades no âmbito hospitalar. O conjunto de "Canais Internos" contempla aqueles considerados “formais”, destinados à comunicação oficial, e os canais “informais” definidos como recursos de interação destinados à sociabilidade.

O tópico "Normativa interna da unidade de comunicação social” abre a segunda parte do documento ora descrito abordando "as atribuições e responsabilidades dos profissionais lotados na unidade de comunicação” (HU-UNIVASF, 2017, p. 16). Registra-se, ainda, os 
produtos e serviços comunicacionais sob a responsabilidade da Unidade de Comunicação Social. Por fim, o tópico "Finalização" reitera e traz novos princípios valorativos às Diretrizes como "respeito aos públicos e ao serviço público” e "responsabilidade socioambiental” (HUUNIVASF, 2017).

\section{Modelo referencial para a avaliação da acessibilidade comunicacional em políticas de comunicação interna de hospitais universitários}

Observa-se que a comunicação acessível em seus diversos aspectos é um imperativo no contexto dos serviços públicos hospitalares (OLIVEIRA, 2012, BRASIL, 2012, SILVA, 2014, MENDES, 2014, CASTRO; ALMEIDA, 2014, SARDAGNA; OLIVEIRA, 2017). Partindo dessa premissa, observa-se a necessidade de parametrizar as recomendações prescritas para arquitetura da política endocomunicacional dos HUs na busca por atender às especificidades do público interno integrado por pessoas com deficiência.

Nesse esforço, o pesquisador recorreu ao embasamento teórico valendo-se dos conhecimentos científicos consolidados pelos autores citados ao longo deste artigo. Além disso, buscou-se respaldo no arcabouço documental do setor público associado ao tema de pesquisa - a exemplo da Política de Comunicação da Empresa Brasileira de Serviços Hospitalares (EBSERH, 2018b), Lei de Acesso à Informação (BRASIL, 2011), Lei da Acessibilidade (BRASIL, 2000) e Constituição Federal do Brasil (BRASIL, 1988).

Sendo assim, enquanto produto de pesquisa, apresentam-se a seguir os critérios que compõem "Modelo referencial para avaliação da Acessibilidade Comunicacional em Políticas de Comunicação Interna de Hospitais Universitários” utilizado na análise das Diretrizes Comunicacionais do HU-Univasf:

Quadro 1 - Modelo referencial para avaliação das boas práticas em Acessibilidade Comunicacional nas Políticas de Comunicação Interna de Hospitais Universitários

\section{Questão motivadora - Quais as boas práticas em Políticas de Comunicação Interna em HUs na promoção da Acessibilidade Comunicacional?}

1. Promulgação dos atributos de Acessibilidade, Inclusão e Equidade/Igualdade como delineadores das atividades comunicacionais no serviço público hospitalar (BRASIL, 1990, 2012, 2015, SARDAGNA; OLIVEIRA, 2017, EBSERH, 2018b, ALVES 2019).

2. Inserção de objetivos claros visando à promoção da Acessibilidade Comunicacional (BRASIL, 1990, 2011, 2012, 2015, CASTRO; ALMEIDA, 2014, SILVA, 2014).

3. Inserção de recursos (canais, produtos...) e estratégias comunicacionais claramente voltadas à promoção da Acessibilidade Comunicacional (BRASIL, 1990, 2011, 2012, SASSAKI, 2006, 2009, SARDAGNA; OLIVEIRA, 2017).

4. Emprego de Tecnologias Assistivas na promoção da Acessibilidade Comunicacional (BRASIL, 2000, 2011, 2012, 2015, SILVA, 2014; SARDAGNA; OLIVEIRA, 2017, FIGUEIRA, 2019). 
Questão motivadora - Quais as boas práticas em Políticas de Comunicação Interna em HUs na promoção da Acessibilidade Comunicacional?

5. Promover a assimilação do comportamento inclusivo e acessível como prática de relacionamento do Público Interno, a fim de romper barreiras atitudinais que configuram entrave para integração efetiva das pessoas com deficiência (SASSAKI, 2006, 2009, BRASIL, 2012, CASTRO; ALMEIDA, 2014, COSTA, 2014, FIGUEIRA, 2019).

6. Norteamento da arquitetura institucional voltada especificamente à Acessibilidade Comunicacional (BRASIL, 2000, 2012, 2015, MENDES, 2014, SARDAGNA; OLIVEIRA, 2017, FALCÃO, 2016, PIMENTEL; PIMENTEL, 2017, EBSERH, 2018b, GALVAN et al., 2019, FIGUEIRA, 2019).

7. Promoção da participação ativa das pessoas com deficiência na avaliação e no desenvolvimento dos fluxos comunicacionais (BRASIL, 2012, OLIVEIRA, 2012, COSTA, 2014, FIGUEIRA, 2019).

8. Viabilização de recursos comunicacionais para que possas com deficiência possam estar inseridas ativamente na "vida social” da organização, extrapolando a atuação meramente operacional (BRASIL, 2000, 2012, COSTA, 2014, FIGUEIRA, 2019).

Fonte: autoria própria (2019).

\section{Resultados da aplicação do modelo avaliativo}

Diante dessa fundamentação, passa-se agora à análise do atributo de Acessibilidade Comunicacional na Política de Comunicação do HU-Univasf. Inicialmente, é válido frisar que os temas “acessibilidade”, “inclusão” e “diversidade” não constam diretamente em nenhuma passagem da Política Comunicacional do HU. Essa ausência sugere a não inserção de recursos e práticas comunicacionais voltadas à atenção das especificidades cognitivas e motoras dos interlocutores intrainstitucionais.

Tal negligência torna-se crítica uma vez que normativas a exemplo do Decreto Federal $n^{\circ}$ 5.296, de 2 de dezembro de 2004 (BRASIL, 2004), determinam que o predicado da acessibilidade deve ser cumprido na prestação de serviços públicos, assim como na condução institucional visando a oferta desses serviços. Além disso, corroborando essa necessidade, para além do aspecto legal, Costa (2014, p. 99) enfatiza que

é preciso caminhar na direção de uma ética da vida, ética que cria as condições para gerar um comum, ali onde é possível que [...] as diferenças circulem [...]. Nesse momento começa a real discussão sobre inclusão social, quando o fato de ser pessoa com deficiência é simplesmente envolvido por sua cidadania, pelo ser humano que ela representa. De qualquer forma, o campo da Saúde estará sempre fendido entre o direito e a ética. Por um lado, as relações reguladas de forma institucional, por outro, a ética que se exerce em cada relação singular, lá onde o direito não pode chegar, nessa região do não direito, onde uma pessoa com deficiência deveria ser vista tão somente como pessoa. 
Fica evidenciada a necessidade de construir um cenário de prestação de serviços em saúde cuja mediação da acessibilidade se baseie em uma ética humanista, capaz de enxergar no outro, independentemente de suas diferenças, uma pessoa com limitações, potenciais e que merece atenção, respeito e recursos de sociabilidade. A ética da acessibilidade, por assim dizer, permite compreender que características particulares fazem parte do conjunto de todos e não somente das pessoas com deficiência.

\section{Estabelecimento de objetivos, responsabilidades e formas de suporte da Comunicação Interna à Acessibilidade Comunicacional}

Dando continuidade à análise, conforme Quadro 2, observa-se que, somente de forma indireta, as Diretrizes Comunicacionais do HU-Univasf trazem instruções quanto à condução dos processos em comunicação visando dirimir possíveis barreiras nas relações com o Público Interno.

Quadro 2 - Diretrizes - Comunicação Interna visando à Acessibilidade Comunicacional

\section{DIRETRIZES: COMUNICAÇÃO INTERNA VISANDO À ACESSIBILIDADE} COMUNICACIONAL (HU-UNIVASF, 2017).

EM QUAL TÓPICO O QUE ESTABELECE

Necessidade de trabalho de comunicação robusto para que as

APRESENTAÇÃO

APRESENTAÇÃO

PRESSUPOSTOS

BÁSICOS informações cheguem a todos os públicos com os quais o HUUnivasf se relaciona. comunicacional a todos os públicos de interesse.

Promoção da "igualdade” como incumbência da comunicação organizacional do HU.
Caberá à Unidade de Comunicação Social prestar suporte

Fonte: adaptado de HU-Univasf (2017).

Tais preceitos podem, à primeira vista, indicar uma inclinação das Diretrizes comunicacionais do HU em garantir fluxos inclusivos e dotados das características necessárias para prover meios de interação e consumo informacional de forma equânime. No entanto, uma análise mais detalhada revela outra realidade. Apesar de estabelecer a necessidade de um trabalho comunicacional que permita o acesso informacional por todos os públicos, as Diretrizes não especificam quais as estratégias ou recursos inclusivos deverão ser aplicadas com essa finalidade.

O mesmo problema ocorre quanto à designação das atividades da Unidade de Comunicação Social-UCS. Segundo o documento aqui estudado, caberá à UCS prestar "suporte comunicacional a todos os públicos de interesse" (HU-UNIVASF, 2017, p. 11). A real possibilidade de cumprimento desse compromisso encontra-se fragilizada, uma vez que, 
novamente, não são elencadas as responsabilidades e métodos comunicacionais dirigidos à Acessibilidade Comunicacional.

De forma semelhante, fica comprometida a possibilidade de cumprimento do atributo da promoção “igualdade” na Comunicação Interna do HU (Quadro 2). Pois, uma vez que não são contempladas objetivamente as estratégias ou canais/rotinas para garantir o acesso informacional equânime, e nem definidos os mecanismos para o atendimento inclusivo das demandas e especificidades do público interno, revela-se infactível a observância do referido atributo.

Dando seguimento à análise do atributo de “Acessibilidade Comunicacional” nas relações com o Público Interno, observam-se as seguintes normativas segundo a política comunicacional do HU-Univasf:

Quadro 3 - Outras diretrizes relacionadas à Comunicação Interna e Acessibilidade Comunicacional

DIRETRIZES: OUTRAS DIRETRIZES RELACIONADAS À COMUNICAÇÃO INTERNA E ACESSIBILIDADE COMUNICACIONAL (HU-UNIVASF, 2017).

\section{EM QUAL TÓPICO O QUE ESTABELECE}

\begin{tabular}{ll}
\hline OBJETIVOS & $\begin{array}{l}\text { Dever de fortalecer a imagem do HU-Univasf perante seus públicos } \\
\text { ESPECInteresse. }\end{array}$ \\
\hline OBJETIVOS & $\begin{array}{l}\text { Dever de fomentar, exercer e divulgar as boas práticas hospitalares } \\
\text { pautadas na humanização, inovação, busca pela excelência. }\end{array}$ \\
\hline ESPECÍFICOS & Compromisso com o desenvolvimento de prática comunicacional \\
BÁSICOS & pautada no respeito aos públicos. \\
\hline
\end{tabular}

Fonte: adaptado de HU-Univasf (2017).

Novamente, uma investigação crítica revela a inconsistência na possibilidade de observância de tais normativas. Para fortalecer a imagem institucional perante os indivíduos, é necessário estabelecer comunicação estratégica e eficiente com todos os públicos, promover campanhas de engajamento, reconhecer as aptidões e contribuições desses agentes perante a instituição e ainda promover a participação ativa do público nos fluxos informacionais (DECKER; MICHEL, 2006).

Por consequência, a não inserção de meios de comunicação inclusivos, capazes de viabilizar a emissão e recepção de mensagens adaptadas às especificidades cognitivas ou motoras do Público Interno, impede a promoção da boa imagem institucional perante esses indivíduos e suas redes de influência. Nessa mesma conjuntura, torna-se incoerente tratar sobre o fomento de "boas práticas hospitalares”, "humanização” e "excelência” em comunicação (Quadro 3), uma vez que é ignorado o planejamento e execução de ações concretas para subsidiar a comunicação inclusiva. 
É importante salientar que, para ser efetiva, a Acessibilidade Comunicacional deve assumir um caráter reflexivo, permitindo não somente que a pessoa com deficiência possa assimilar o conteúdo técnico e simbólico necessários à sociabilidade. Significa também propiciar o papel ativo desse sujeito, enquanto protagonista do contexto social no qual esteja inserido, podendo também construir e entregar conteúdo aos demais interlocutores. “O ‘ajuste mútuo' entre pessoas com deficiência e sociedade aponta para esse sentido de participação, colaboração, cooperação na construção dos recursos sociais. Assim, ter 'acesso a recursos' é participar simultaneamente de sua elaboração, produção, construção” (COSTA, 2014, p. 99).

Quanto ao "compromisso com o desenvolvimento de prática comunicacional pautada no respeito aos públicos” (Quadro 3), compreende-se que não se pode conceber o respeito à totalidade do Público Interno sem atentar-se para as necessidades comunicacionais específicas dos indivíduos que compõem esse público. Ignorar esse fator mina o direto de Acesso à Informação (BRASIL, 2011) e impossibilita a participação social de maneira equânime nos processos avaliativos e decisórios no âmbito do Hospital Universitário.

Além disso, a não promoção efetiva da inclusão contribui para a segregação de parcelas do público e impede o reconhecimento das competências das pessoas com deficiência. Conforme alertam Rocha e Miranda (2009, p. 33), uma estratégia de inclusão ineficiente contribui para "isolar grupos, para criar guetos e, consequentemente, para aumentar, na sociedade, a fragmentação que se quer eliminar".

Sendo assim, nesse cenário não inclusivo, a comunidade hospitalar deixa de ser beneficiada pelo trabalho operacional e intelectual das pessoas com deficiência; colaboração que poderia ser potencializada caso houvesse um cenário comunicacional efetivamente acessível. Essa impossibilidade reflete em prejuízo causado a todos os públicos de interesse do HU pela falta do cumprimento do atributo da Acessibilidade Comunicacional.

Nesse sentido, Costa (2014, p. 99) esclarece que o processo de inclusão não pode ser tratado somente

na linha de acesso a serviços, mas também de acesso aos meios imateriais, que se caracteriza, sobretudo, pela produção de um comum, que é a marca do pertencimento dos indivíduos ao campo social, o fato de que cada um colabora na construção da sociedade e, portanto, a pessoa com deficiência também se insere nesse processo, ela também deve participar dessa construção.

Portanto, o relato depreendido até aqui revela a necessidade de reformulação da política comunicacional do HU-Univasf no tocante à Acessibilidade Comunicacional com foco no Público Interno da instituição. É válido salientar que as normativas do SUS estabelecem o princípio da equidade enquanto fundamento para prestação dos serviços em saúde pública (BRASIL, 1990).

Sendo assim, a não inserção das temáticas de acessibilidade, inclusão e diversidade no conjunto de tratativas das diretrizes aponta para uma lacuna conceitual e operacional 
que necessita ser resolvida ante os imperativos legais, científicos e sociais pela construção de um serviço público equânime. Corroborando esse raciocínio, apresenta-se a seguir, no Quadro 4, os resultados consolidados da aplicação do "Modelo referencial para avaliação das boas práticas em Acessibilidade Comunicacional nas Políticas de Comunicação Interna de Hospitais Universitários" na análise das "Diretrizes de Comunicação Institucional e Normativa Interna da Unidade de Comunicação Social do Hospital Universitário da Univasf”:

Quadro 4 - Resultados Consolidados

\section{MODELO REFERENCIAL PARA A AVALIAÇÃO DAS BOAS PRÁTICAS EM ACESSIBILIDADE COMUNICACIONAL NAS POLÍTICAS DE COMUNICAÇÃO INTERNA DE HOSPITAIS UNIVERSITÁRIOS}

\section{CRITÉRIOS}

Promulgação dos atributos de Acessibilidade, Inclusão e Equidade/Igualdade como delineadores das atividades comunicacionais no serviço público hospitalar.

\section{AVALIAÇÃO DA POLÍTICA DO HU-} UNIVASF

Somente o atributo da "igualdade" é inserido na Política de Comunicação Interna do HU.

\begin{tabular}{l} 
Inserção de objetivos claros visando à promoção \\
da Acessibilidade Comunicacional. \\
\hline Inserção de recursos (canais, produtos...) e \\
estratégias comunicacionais claramente voltadas à \\
promoção da Acessibilidade Comunicacional. \\
Emprego de Tecnologias Assistivas na promoção \\
da Acessibilidade Comunicacional.
\end{tabular}

Promover a assimilação do comportamento inclusivo e acessível como prática de relacionamento do Público Interno a fim de romper barreiras atitudinais que configuram entrave para a integração efetiva das pessoas com deficiência.
Não apresenta diretrizes que atendam objetivamente a essa recomendação. Não apresenta diretrizes que atendam objetivamente a essa recomendação.

Não apresenta diretrizes que atendam objetivamente a essa recomendação. Não apresenta diretrizes que atendam objetivamente a essa recomendação.
Norteamento da arquitetura institucional voltada
especificamente à Acessibilidade Comunicacional.

Promoção da participação ativa das pessoas com deficiência na avaliação e desenvolvimento dos fluxos comunicacionais.

Viabilização de recursos comunicacionais para que as pessoas com deficiência possam estar inseridas ativamente na "vida social” da organização, extrapolando a atuação meramente operacional.
Não apresenta diretrizes que atendam objetivamente a essa recomendação.

Não apresenta diretrizes que atendam objetivamente a essa recomendação. Não apresenta diretrizes que atendam objetivamente a essa recomendação.

Fonte: autoria própria (2019). 


\section{Considerações finais}

A elaboração e aplicação do "Modelo referencial para avaliação das boas práticas em Acessibilidade Comunicacional nas Políticas de Comunicação Interna de Hospitais Universitários", erigido a partir das etapas descritas na seção "Percurso Metodológico", demonstrou-se satisfatória, provendo diagnóstico multifatorial fundamentado em parâmetros científicos e normativo-legais. Dentre os problemas detectados na Política de Comunicação Interna do HU-Univasf através da aplicação do modelo proposto, foi considerada crítica a ausência de recursos endocomunicacionais para garantia da Acessibilidade Comunicacional.

Através da avaliação realizada, observou-se que a falta de inserção do atributo da acessibilidade entre os princípios e objetivos comunicacionais reverbera negativamente no restante do documento estudado; de modo que a política do HU não provê de maneira clara qualquer tipo de recurso ou conduta para o alcance de um cenário comunicacional interno acessível.

Conforme Mendes (2014), compreende-se que a não abordagem sobre acessibilidade em instituições é recorrente. Para o autor, a resolução desse problema demanda inicialmente "superar o imaginário de que as deficiências introduzem complexidades adicionais, uma vez que o discurso que deriva desse imaginário narra dificuldades que revelam desconhecimento e falta de experiência no trato com as pessoas com eficiência” (MENDES, 2014, p. 41).

Em seguida, é necessária a transformação institucional prática através de atitudes, metodologias e aparatos técnicos e simbólicos voltados ao desenvolvimento da Acessibilidade Comunicacional, a fim de que as pessoas com deficiência possam participar passiva ou ativamente dos fluxos informacionais. Nesse sentido, para a política endocomunicacional do HU-Univasf, recomenda-se a inserção da busca pela Acessibilidade Comunicacional enquanto princípio inegociável das práticas hospitalares.

Além disso, a adoção de tecnologias assistivas pode auxiliar o cumprimento desse objetivo, na medida em que

proporcionam à pessoa com deficiência maior independência, qualidade de vida e inclusão social, pois viabilizam a ampliação de sua comunicação, mobilidade, controle de seu ambiente, facilitando o desenvolvimento de habilidades e de condições para seu aprendizado, trabalho e integração com a família, amigos e sociedade (ROCHA; MIRANDA, 2009, p. 27).

Contudo, a real consecução da promoção da igualdade social e do respeito ao público, como aparentemente almeja a Política de Comunicação interna do HU, somente será alcançado através da efetiva participação de todas as parcelas do público interno, principalmente as pessoas com deficiência, na problematização e proposição de soluções ante os desafios concretos e simbólicos vivenciados pela comunidade hospitalar. 


\section{Referências}

ABRACOM. Como entender a Comunicação Interna: caderno de Comunicação Organizacional da Associação Brasileira de Agências de Comunicação - ABRACOM. São Paulo: Suzano Papel e Celulose, 2008. ALVES, A. Acessibilidade e princípios dos SUS. Parte I. Módulo 3. Acessibilidade: barreiras e soluções. Rio de Janeiro: Fiocruz/Icict, 2019.

ANJOS, M. Uso do Open Patent Services na busca de soluções voltadas à contenção de pacientes em Centros de Atenção Psicossocial - CAPS. 2018. 104 f. Dissertação (Programa de Mestrado Profissional em Administração - Gestão em Sistemas de Saúde) - Universidade Nove de Julho, São Paulo, 2018.

ARMANI, D. Mobilizar para transformar: a mobilização de recursos nas organizações da sociedade civil. Editora Peirópolis, 2008.

ASSIS, L.; SILVA, C. Aplicabilidade do Planejamento Estratégico em Hospitais Universitários Federais. Revista de Gestão em Sistemas de Saúde, v. 5, n. 2, 2016.

BELTRAME, M.; ALPERSTEDT, G. Construção de política de comunicação em instituições de educação profissional, científica e tecnológica: uma proposta com base na experiência do IFSC. Navus - Revista de Gestão e Tecnologia, v. 5, n. 2, 2015.

BRASIL. Constituição da República Federativa do Brasil de 1988. Disponível em: http://www.planalto. gov.br/ccivil_03/constituicao/constituicao.htm. Acesso em: 27 jul. 2018.

BRASIL. Lei no 13.146, de 6 de julho de 2015. Institui a Lei Brasileira de Inclusão da Pessoa com Deficiência (Estatuto da Pessoa com Deficiência). Diário Oficial da União, 2015.

BRASIL. Lei $\mathrm{n}^{\circ}$ 10.098, de 19 de dezembro de 2000. Estabelece normas gerais e critérios básicos para a promoção da acessibilidade das pessoas portadoras de deficiência ou com mobilidade reduzida, e dá outras providências. Diário Oficial da União, 2000.

BRASIL. Lei nº 8.080, de 19 de setembro de 1990. Dispõe sobre as condições para a promoção, proteção e recuperação da saúde, a organização e o funcionamento dos serviços correspondentes e dá outras providências. Diário Oficial da União, 1990.

BRASIL. Acesso à informação pública: uma introdução à Lei no 12.527, de 18 de novembro de 2011. Anuário de Brasília (DF), 2011.

BRASIL. Portaria n 793, de 24 de abril de 2012. Institui a Rede de Cuidados à Pessoa com Deficiência no âmbito do Sistema Único de Saúde. Diário Oficial da União, 2012.

BORGES, S. Sustentabilidade \& acessibilidade: educação ambiental, inclusão e direitos da pessoa com deficiência - práticas, aproximações teóricas, caminhos e perspectivas. Brasília: OAB Editora, 2014.

BUENO, W. Comunicação Empresarial: alinhando teoria e prática. Barueri: Manole, 2014a.

BUENO, W. A construção de uma Política de Comunicação como processo de legitimação da comunicação pública no Brasil. Revista Comunicação Midiática, v. 9, n. 3, 2014 b.

BUENO, W. As redes sociais e a imagem das organizações. Agência Alvo verde Jornalismo, São Paulo, 2014c.

BUENO, W. Política de Comunicação: só poucas organizações podem ter. Belo Horizonte: RH PortalSolidez, 2015a.

BUENO, W. Política de Comunicação do IFRS: conceito, metodologia e participação. Bento Gonçalves, Editora Tesius: 2015b. 
CASTRO. S.; ALMEIDA, M. Ingresso e Permanência de Alunos com Deficiência em Universidades Públicas Brasileiras. Revista Brasileira de Educação Especial, v. 20, n. 2, 2014.

COSTA JÚNIOR, A.; COSTA, C. A Comunicação como Efetivação da Transparência na Gestão Pública: um estudo de caso em uma Prefeitura Municipal no interior do Nordeste. Revista Temática, v. 10, n. 2, 2014.

CRESWELL, J. Projeto de Pesquisa: métodos qualitativo, quantitativo e misto. 2a. ed. Porto Alegre: Artmed, 2007.

DECKER, C.; MICHEL, M. A imagem nas organizações públicas: uma questão de política, poder, cultura e comunicação - Estudo de caso INSS em Pelotas, 2006. Disponível em: http://www.bocc.ubi.pt/pag/deckercleiton-michel-margaret-imagem-nas-organizacoes.pdf. Acesso em: 12 nov. 2018.

DESIMON, S.; BATIZ, E. Método de desenvolvimento conceitual de tecnologias assistivas hospitalares: design de uma cadeira ergonômica para tratamento em hemodiálise. Produção em Foco, v. 2, n. 1, 21 dez. 2012.

DUARTE, J. Comunicação Pública. In: DUARTE, J. Comunicação e Crise. Brasília, 2007a.

DUARTE, J. Instrumentos de Comunicação Pública. In: DUARTE, J. (Org.). Comunicação Pública: Estado, Mercado, Sociedade e Interesse Público. São Paulo - SP: Atlas, 2007b.

EBSERH, Empresa Brasileira de Serviços Hospitalares. Política de Comunicação da Ebserh, 2018. Disponível em: http://www2.ebserh.gov.br/documents/14003/3153409/ Pol\%C3\%ADtica+de+Comunica\%C3\%A7\%C3\%A3o+Institucional+Ebserh+Aprovada+CA.pdf/b6d347a1bd76-414a-b862-22551e70c7fc. Acesso em: 4 fev. 2019.

FALCÃO, C. Diretrizes projetuais para recepções setoriais de hospitais universitários federais. 2016. 240f. Dissertação (Mestrado em Ergonomia). Universidade Federal da Pernambuco (UFPE), Centro de Artes e Comunicação, Recife-PE, 2016.

FIGUEIRA, E. O legado de Emílio Figueira à Inclusão Brasileira. 1a. ed. São Paulo: Agbook /Acervo Inclusivo, 2019.

FIGUEIREDO, A. et al. Uso terapêutico de tecnologias assistivas: direitos das pessoas com deficiência e visão. Belo Horizonte: Nescon/UFMG, 2015.

GALVAN, L. et al. Análise da acessibilidade no centro de tratamento da criança com câncer de um hospital universitário. Cadernos Brasileiros de Terapia Ocupacional, São Carlos , v. 27, n. 1, p. 81-91, jan. 2019 .

GIL, A. Métodos e Técnicas de Pesquisa Social. 6a. ed. São Paulo: Atlas, 2008.

HU-UNIVASF. Hospital Universitário da Universidade Federal do Vale do São Francisco. Diretrizes de Comunicação Institucional e Normativa Interna da Unidade de Comunicação Social do HU-Univasf, 2017. Disponível em: http://www2.ebserh.gov.br/web/hu-univasf/diretrizes-de-comunicacao-institucional. Acesso em: 4 fev. 2019.

KUNSCH, M. Comunicação pública: direitos de cidadania, fundamentos e práticas. In: MATOS, H. (Org.). Comunicação pública: interlocuções, interlocutores e perspectivas. São Paulo - SP, ECA-USP/CECORP, 2012.

LUNA, S. Planejamento de pesquisa: uma introdução. São Paulo: Educ, 2002.

MARCONI, M.; LAKATOS, E. Fundamentos de Metodologia Científica. São Paulo: Atlas, 2003.

MENDES, V. Da "narrativa da dificuldade” ao diálogo com a diferença: construindo a Rede de Cuidados à Saúde da Pessoa com Deficiência. Ministério da Saúde (org.). In: Diálogo (bio)político sobre alguns desafios da construção da Rede de Cuidados à Saúde da Pessoa com Deficiência do SUS. Brasília - DF: Ministério da Saúde, 2014. 
MIRENO, G. et al. Contribuições do Design na promoção da autonomia em um Hospital Psiquiátrico de Santa Catarina. In: XIII-CONGRESSO BRASILEIRO DE PESQUISA E DESENVOLVIMENTO EM DESIGN. Joinville: UNIVELLE, 2018. Anais....

MORO, E. et al. Projeto Cor@gem: o acesso e o uso das TICs entre pacientes hospitalizados e a interação em ambientes virtuais de aprendizagem. Inclusão Social, v. 2, n. 2, 7 maio 2008.

NASSAR, M. Novas Tecnologias de Comunicação em Hospitais: a Internet como Estratégia para Gestão do Relacionamento com os Públicos. In: CONGRESSO BRASILEIRO DE CIÊNCIAS DA COMUNICAÇÃO. Natal: UFRN, 2008. Anais....

NOGUEIRA, H.; REINALDO, P.; MAYER, V. Comunicação interna no âmbito da gestão pública: o caso de uma autarquia pública federal brasileira. REGE. Revista de Gestão USP, v. 20, 2013.

NORONHA, D.; FERREIRA, S., Revisões da Literatura. In: CAMPELLO, B.; CENDÓN, B.; KREMER, J. (Org.). Fontes de Informação para Pesquisadores e Profissionais. 2a. Reimpressão. Belo Horizonte: Editora UFMG, 2007.

NUNES, A. A comunicação universidade-sociedade. In: XIV ENCONTRO DOS GRUPOS DE PESQUISA EM COMUNICAÇÃO - Relações Públicas e Comunicação Organizacional. Foz do Iguaçu: UDC, 2014. Anais....

OLIVEIRA, M. Comunicação organizacional e comunicação pública In: MATOS, H. (Org.). Comunicação pública: interlocuções, interlocutores e perspectivas. São Paulo - SP, ECA-USP/CECORP, 2012.

PIMENTEL, S.; PIMENTEL, M. Acessibilidade para inclusão da pessoa com deficiência: sobre o que estamos falando? Revista FAEEBA. Salvador, v. 26, n. 50, 2017.

PINHO, J. Propaganda institucional: usos e funções da propaganda em relações públicas. São Paulo: Summus, 1991.

PRODANOV, C.; FREITAS, E. Metodologia do Trabalho Científico: Métodos e Técnicas de Pesquisa e do Trabalho Acadêmico. 2a. ed. Novo Hamburgo: FREEVALE, 2013.

RAMÃO, G. Utilização de informações patentárias na busca de soluções inovadoras para o setor de atendimento hospitalar. 2017. 100 f. Dissertação (Programa de Mestrado Profissional em Administração Gestão em Sistemas de Saúde). Universidade Nove de Julho, São Paulo, 2017.

RESENDE, L. et al. Uso terapêutico de tecnologias assistivas: direitos das pessoas com deficiência e audição. Belo Horizonte: Nescon/UFMG, 2015.

ROCHA, T.; MIRANDA, T. A inclusão de alunos com deficiência no ensino superior: uma análise de seu acesso e permanência. In: DÍAZ, F.; BORDAS, M.; GALVÃO, N.; MIRANDA, T. (Org.). Educação inclusiva, deficiência e contexto social: questões contemporâneas. 1a. ed. Salvador: Edufba, 2009.

SAMPIERI, R.; CALlADO, C.; LUCIO, M. Metodologia de Pesquisa. 5a. ed. São Paulo: Penso, 2013.

SARDAGNA, H.; OLIVEIRA, S. Pesquisa e Produção de Tecnologia Assistiva: Promovendo Inclusão e Acessibilidade. Pleiade-Uniamérica. v. 11, n. 22, 2017.

SARRAF, V. P. Acessibilidade em Espaços Culturais: mediação e comunicação sensorial. São Paulo: EDUC: FAPESP, 2016.

SASSAKI, R. Inclusão: acessibilidade no lazer, trabalho e educação. Revista Nacional de Reabilitação (Reação), São Paulo, ano 12, n. 67, p. 10-16, mar./abr. 2009.

SASSAKI, R. Inclusão: Construindo Uma Sociedade Para Todos. 7a. ed. Rio de Janeiro: WVA, 2006. 
SCHMENGLER, A.; FREITAS, S.; PAVÃO, S. Acessibilidade no atendimento educacional de alunos públicoalvo da Educação Especial em uma Classe Hospitalar do estado do Rio Grande do Sul. Práxis Educativa, Ponta Grossa, v. 13, n. 1, p. 128-144, jan./abr. 2018.

SILVA, L. Acessibilidade físico-espacial em hospital público na percepção dos usuários com deficiência: estudo de caso nas áreas externas e acessos de hospital universitário em Joao Pessoa-PB. 2014. 131f. Dissertação (Mestrado em Arquitetura e Urbanismo). Universidade Federal da Paraíba (UFPB), Centro de Tecnologia, João Pessoa-PB, 2014.

VERGARA, S. Projetos e Relatórios de Pesquisa em Administração. 14a. ed. São Paulo: Atlas, 2013.

VIGNERON, J. Comunicação interna além das mídias. Revista Líbero, v. 4, n. 7, 2000.

WRIGHT, P.; KROLL, M.; PARNELL, J. Administração estratégica: conceitos. 1a. ed. SãoPaulo: Atlas, 2000.

\section{Francisco Ricardo Duarte}

Possui graduação em Administração pela Universidade Estadual de Londrina (UEL/1997), em Filosofia pela Faculdade Católica de Anápolis (FCA/2010) e em Pedagogia pela Universidade Federal do Piauí (UFPI/2018). Especialista em Administração, Orientação e Supervisão Escolar pela Universidade Norte do Paraná (UNOPAR/2004), em Metodologias de Ensino da Filosofia pela Universidade Gama Filho (UGF/2010) e, também, em Gestão de Pessoas com ênfase em Gestão por Competências pela Universidade Federal da Bahia (UFBA/2018). Mestre em Administração (Gestão de Negócios) pela Universidade Estadual de Londrina (UEL/2002). Doutor em Difusão do Conhecimento pela Universidade Federal da Bahia (UFBA, 2012). É Professor Associado I da Fundação Universidade Federal do Vale do São Francisco. Atualmente, é Coordenador Adjunto do Mestrado Profissional em Administração Pública (PROFIAP/UNIVAS). E-mail: francisco. duarte@univasf.edu.br.

\section{Allan Richards de Melo Nunes Morais}

Possui graduação em Comunicação Social - Jornalismo e Multimeios pela Universidade do Estado da Bahia (2011), especialização em Ensino Superior: Contemporaneidade e Novas Tecnologias e Mestrado em Administração Pública pela Universidade Federal do Vale do São Francisco (Univasf). Tem experiência na área de Comunicação, com ênfase em Comunicação Organizacional. E-mail: allandemorais@yahoo.com.br.

Recebido em: 28.02.2019

Aprovado em: 17.09.2020

Este artigo é publicado em acesso aberto (Open Access) sob a licença Creative Commons Attribution Non-Commercial (CC-BY-NC), que permite uso, distribuição e reprodução em qualquer meio, sem restrições, desde que sem fins comerciais e que o trabalho original seja corretamente citado.

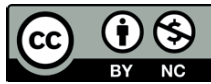

